\title{
Uso da somatotropina recombinante bovina em búfalas leiteiras I: produção e composição físico-química do leite
}

\author{
[Use of recombinant bovine somatotropin (rbST) in dairy buffaloes I: production and \\ physicochemical composition of milk] \\ W.O. Melo ${ }^{1}$, B.M. Monteiro ${ }^{2}$, L.C.S. Chaves $^{3}$, E.R.D. Santos ${ }^{4}$, A.P. Leão ${ }^{3}$, G.M. Bragança ${ }^{5}$, \\ C. Faturi ${ }^{3}$, J.D. Ribeiro Filho ${ }^{6}$, S.P. Faria Júnior ${ }^{7}$, R.B. Viana ${ }^{3}$ \\ ${ }^{1}$ Universidade Federal Rural da Amazônia - Paragominas, PA \\ ${ }^{2}$ Universidade de São Paulo - São Paulo, SP \\ ${ }^{3}$ Universidade Federal Rural da Amazônia - Belém, PA \\ ${ }^{4}$ Zootecnista autônomo \\ ${ }^{5}$ Universidade Federal Fluminense - Niterói, RJ \\ ${ }^{6}$ Universidade Federal de Viçosa - Viçosa, MG \\ ${ }^{7}$ Livestock Technical Manager - MSD Saúde Animal - São Paulo, SP
}

\begin{abstract}
RESUMO
Objetivou-se avaliar a influência da somatotropina recombinante bovina (rbST) sobre a produção e os constituintes do leite de búfalas entre 63 e 154 dias em lactação. Foram utilizadas 22 búfalas, distribuídas em dois grupos experimentais: grupo rbST - aplicação de $500 \mathrm{mg}$ de rbST a cada 14 dias; grupo controle sem aplicação de rbST. A cada sete dias, foi aferida a produção de leite de todas as búfalas e coletada uma amostra para análise físico-química. As variáveis produtivas e as oriundas de análises laboratoriais foram avaliadas como medidas repetidas no tempo, utilizando-se o comando Repeated gerado pelo procedimento GLM do SAS. A média dos parâmetros estudados para os grupos rbST e controle foram, respectivamente: produção de leite - 6,54 vs. 6,68 kg; gordura - 6,31 vs. 6,34\%; proteína 3,86 vs. 3,81\%; lactose - 4,96 vs. 5,02\%; sólidos totais - 16,05 vs. 16,03\%; extrato seco desengordurado - 9,75 vs. 9,74\%; contagem de células somáticas - 329,90 vs. 171,68 (x 1000/mL); e elecondutividade - 2,87 vs. $2,81 \mathrm{mS} / \mathrm{cm}$. A utilização de $500 \mathrm{mg}$ de rbST administrados quinzenalmente, entre 63 e 154 dias em lactação não alterou a produção de leite, a proporção dos constituintes e a CCS do leite de búfalas leiteiras.
\end{abstract}

Palavras-chave: búfalos, hormônio do crescimento, produção de leite, constituintes do leite

\begin{abstract}
This study aimed to evaluate the effect of recombinant bovine somatotropin (rbST) on milk yield and the proportion of buffalo milk components during lactation. Twenty-two buffaloes randomly distributed in two experimental groups were used: Group rbST - application of 500mg rbST every 14 days, between 63 and 154 days in milk (DIM); Control Group - without treatment. Weekly, the milk yield of buffaloes was measured and a sample was collected for physicochemical analysis. The response variables were evaluated as repeated measures, using the Repeated procedure through the GLM procedure of SAS. Means of each variable after rbST and Control were: Milk yield - 6,54 vs. 6,68 kg; Fat - 6,31 vs. 6,34\%; Protein - 3,86 vs. 3,81\%; Lactose - 4,96 vs. 5,02\%; Milk solids - 16,05 vs. 16,03\%; Defatted dry matter9,75 vs. 9,74\%; Somatic Cells Count - 329,90 vs. 171,68 (x 1000/mL); and electrical conductivity-2,87 vs. $2,81 \mathrm{mS} / \mathrm{cm}$. The use of $500 \mathrm{mg}$ of rbST administered every two weeks, between 63 and 154 DIM did not affect milk yield, proportion of milk constituents and SCC of dairy buffaloes.
\end{abstract}

Keywords: buffalo, growth hormone, milk yield, milk constituents

Recebido em 1 de fevereiro de 2017

Aceito em 7 de junho de 2017

E-mail: waldjaniomelo@zootecnista.com.br 


\section{INTRODUÇÃO}

O mercado para produtos lácteos de origem bubalina se encontra em crescimento da ordem de $20 \%$ ao ano no Brasil, fato que tem levado os produtores a buscar técnicas que aumentem a produção de leite e a proporção de sólidos totais para a industrialização (Gonsalves Neto et al., 2009). Entre as técnicas disponíveis para melhorar a eficiência e a rentabilidade das propriedades leiteiras, está o uso da somatotropina recombinante bovina (rbST), uma biotétcnica muito difundida para aumentar a produção de leite e a persistência da lactação de vacas leiteiras de alta produção (Rodrigues, 2008).

Também conhecida como hormônio do crescimento (STH), a somatotropina possui mecanismo de ação que envolve uma série de arranjos metabólicos no tecido animal, direcionando nutrientes para a glândula mamária, caracterizando-se como um excelente coordenador de nutrientes que aumenta a eficiência biológica para a síntese de leite (Bauman, 1992). Portanto, a administração de rbST contribui para a eficiência da atividade leiteira, promovendo aumentos da produção que variam de 3 a 40\%, bem como na persistência da lactação, sem alterações nos teores de gordura, proteína, lactose (Santos et al., 2001) e no número de células somáticas do leite (TarazonHerrera et al., 2000; Dohoo et al., 2003; Feckinghaus, 2009).

Alguns estudos têm sido realizados para verificar a influência desse hormônio sobre os constituintes do leite de búfalas (Santos et al., 2001; Jorge et al., 2002; Prasad e Singh, 2010). Entretanto, os efeitos da rbST sobre a produção e a composição do leite, assim como o comportamento da curva de lactação em búfalas ainda são muito variáveis e controversos, principalmente quando comparados com os efeitos bem conhecidos nas vacas.

Desse modo, fazem-se necessárias pesquisas que descrevam a ação da rbST em búfalas leiteiras, não somente sobre a produção de leite, mas também sobre a influência desse fármaco sobre os constituintes do leite e a flutuação deles ao longo da lactação. Assim objetivou-se, com este estudo, quantificar os efeitos da rbST sobre a produção de leite, os constituintes e o número de células somáticas no leite durante a lactação de búfalas. Há a hipótese de que a aplicação contínua de rbST ao longo da lactação aumenta a produção de leite das búfalas, entretanto sem alterar as concentrações dos constituintes e a quantidade de células somáticas do leite.

\section{MATERIAL E MÉTODOS}

O experimento foi aprovado pelo Comitê de Ética no Uso de Animais da UFRA, Protocolo 021/2016 (Ceua) - 23084.006670/2016-28 (Ufra), no qual foram atendidas todas as exigências da Lei Federal 11.794/08 (Lei Arouca), sendo respeitados os Princípios Éticos da Experimentação Animal do Cobea.

O experimento foi conduzido em uma fazenda localizada no município de Moju, na Mesorregião Nordeste do Estado do Pará. O clima da região onde se localiza a propriedade em estudo é caracterizado como Ami (quente úmido), de acordo com a classificação de Köppen, com temperatura média anual entre 25 e $27^{\circ} \mathrm{C}$ e precipitação anual entre 2.000 e 3.000 $\mathrm{mm} / \mathrm{m}^{2}$, com distribuição irregular. A umidade relativa do ar é elevada, com índice de umidade relativa anual média de 77,9\% (Azevedo et al., 2011).

Utilizaram-se 22 búfalas adultas de diferentes grupamentos genéticos, em sua maioria matrizes da raça Murrah (Bubalus bubalis) ou mestiças com predominância genética Murrah. Todas as búfalas eram multíparas, lactantes com partos eutócicos, com média de $66 \pm 1,74$ dias em lactação (DEL) e 6,97 $\pm 1,55$ litros de leite por dia, em duas ordenhas diárias. Os animais foram mantidos em sistema de pastejo rotacionado em Brachiaria (syn. Urochloa) humidicola (Quicuio da Amazônia), Brachiaria (syn. Urochloa) brizantha e Panicum maximum cv. Mombaça, recebendo água e sal mineral ad libitum. Adicionalmente às pastagens, as búfalas em lactação recebiam o quantitativo de $1 \mathrm{~kg}$ de ração/dia, constituída por $30,61 \%$ de torta de murumuru (Astrocaryum murumuru), 61,29\% de farelo de milho (Zea mays), 3,1\% de núcleo mineral e $5 \%$ de ureia. Realizou-se a análise bromatológica da ração na Universidade Federal Rural da Amazônia, campus de Parauapebas PA, adotando-se a metodologia descrita por Silva e Queiroz (2009) (Tab. 1). 
As búfalas foram distribuídas aleatoriamente em dois grupos experimentais, de modo que o primeiro grupo foi composto por 11 búfalas que receberam a aplicação de $500 \mathrm{mg}$ de somatotrotopina bovina recombinante (Grupo rbST; 2 mL de Boostin - MSD Saúde Animal) a cada 14 dias, por via subcutânea, na fossa ísquioretal, alternando-se os lados esquerdo e direito a cada aplicação, totalizando sete aplicações, sendo primeira aos 63 dias em lactação e a última aos 154 dias em lactação. O segundo grupo foi constituído de 11 búfalas que não receberam aplicação de rbST (grupo controle).

Tabela 1. Composição bromatológica da ração fornecida para as búfalas leiteiras

\begin{tabular}{lc}
\hline \multicolumn{3}{c}{ Composição bromatológica } \\
$\begin{array}{c}30,61 \% \text { de torta de murumuru }+61,29 \% \text { de } \\
\text { farelo de milho }+3,1 \% \text { de núcleo mineral e } 5 \%\end{array}$ \\
\hline \multicolumn{2}{c}{ de ureia } \\
\hline Matéria seca (\%) & 93,02 \\
Matéria mineral (\%) & 8,41 \\
Proteína bruta (\%) & 18,17 \\
Extrato etéreo (\%) & 3,15 \\
Fibra em detergente neutro (\%) & 23,9 \\
Fibra em detergente ácido (\%) & 10,96 \\
\hline
\end{tabular}

As ordenhas eram realizadas manualmente, duas vezes ao dia, com intervalo médio de 12 horas entre as mesmas. $\mathrm{O}$ controle da produção de leite foi realizado semanalmente, com esgota total prévia de 12 horas, nos intervalos 63-70; 77-84; 91-98; 105-112; 119-126; 133-140; e 147-154 dias em lactação.

A cada sete dias, foram coletadas amostras de leite em frascos estéreis (identificados) contendo microtabletes de conservantes à base de bronopol e acondicionadas em caixas térmicas contendo gelo reciclável. Em seguida, foram encaminhadas à Clínica do Leite/Escola Superior Luís de Queiroz (ESALQ/USP), em PiracicabaSP, credenciado na Rede Brasileira de Controle de Qualidade do Leite, para a determinação dos teores de gordura $(\% \mathrm{~m} / \mathrm{m})$, proteína $(\% \mathrm{~m} / \mathrm{m})$, lactose $(\% \mathrm{~m} / \mathrm{m})$, extrato seco desengordurado (ESD) $(\% \mathrm{~m} / \mathrm{m})$ de sólidos totais $(\% \mathrm{~m} / \mathrm{m})$, avaliadas pelo método infravermelho-PO ANA 009 e contagem de células somáticas (CCS) (x $1000 / \mathrm{mL}$ ) determinada pelo método de citometria de fluxo - PO ANA 008.
Também foram coletadas alíquotas de leite em frascos estéreis (identificados) sem conservantes, com capacidade para $75 \mathrm{~mL}$, e acondicionadas em caixas térmicas contendo gelo reciclável. Em no máximo 24 horas, foram encaminhadas à Universidade Federal Rural da Amazônia - Ufra (Belém-PA) para determinação dos valores de eletrocondutividade $(\mathrm{mS} / \mathrm{cm})$ pelo método automatizado do aparelho ultrassônico (EKOMILK total ${ }^{\circledR}$, Eon Trading LLC, Bulgária), conforme recomendações do fabricante.

A estatística descritiva dos dados, representada pelas médias aritméticas e o desvio padrão (DP) de cada tratamento, foi obtida pelo procedimento Means do programa SAS, versão 9.2. As variáveis oriundas de análises laboratoriais foram avaliadas como medidas repetidas no tempo, referentes aos momentos de coleta dos dados (tempo) de acordo com cada tratamento (rbST e controle) e suas interações (tratamento*tempo), utilizando-se o comando Repeated gerado pelo procedimento GLM do SAS. Realizaramse os testes de normalidade dos resíduos e homogeneidade das variâncias de cada tempo. Os dados que não preencheram os pressupostos para a análise de variância (ANOVA) foram transformados em conformidade.

Quando a premissa de esfericidade não foi respeitada $(\mathrm{P}<0,05)$, as probabilidades de tempo ( $\mathrm{P}$ tempo) e das interações dos tratamentos com o tempo (P trat*tempo) foram corrigidas pelo teste de GreenhouseGeisse Epsilon. A comparação entre as médias dos grupos dentro de cada tempo (trat/tempo) foi realizada por meio do teste de médias Least Square Means (LSMeans) do SAS. Foi utilizado o nível de significância de $5 \%$ para todos os testes realizados.

\section{RESULTADOS E DISCUSSÃO}

Não houve efeito de tratamento (controle e rBST) para nenhuma das variáveis estudadas (Tab. 2). Em contrapartida, foi observado efeito de tempo de lactação para produção de leite, proteína, lactose, ST, ESD e CCS, assim como efeito de interação (tratamento*tempo) para produção de leite. 
Tabela 2. Média e desvio padrão (DP) da produção de leite $(\mathrm{kg})$, constituintes do leite $(\% \mathrm{~m} / \mathrm{m})$ e contagem de células somáticas (x 1000/mL) no leite de búfalas tratadas com somatotropina recombinante bovina (rbST) ou não (controle) durante a lactação

\begin{tabular}{lccccccc}
\hline & \multicolumn{2}{c}{ Controle } & \multicolumn{2}{c}{ rBST } & \multicolumn{3}{c}{ valor de P } \\
\cline { 2 - 8 } & Média & DP & Média & DP & Tratamento & Tempo & Trat*Tempo \\
\hline Produção de leite $(\mathrm{kg})$ & 6.68 & 1.93 & 6.54 & 2.38 & 0,6219 & $<0,0001$ & 0,0053 \\
Gordura $(\% \mathrm{~m} / \mathrm{m})$ & 6.34 & 1.24 & 6.31 & 1.39 & 0,9341 & 0,0067 & 0,6753 \\
Proteína $(\% \mathrm{~m} / \mathrm{m})$ & 3.81 & 0.56 & 3.86 & 0.31 & 0,7956 & 0,0004 & 0,8904 \\
Lactose $(\% \mathrm{~m} / \mathrm{m})$ & 5.02 & 0.18 & 4.96 & 0.27 & 0,3439 & 0,0350 & 0,1977 \\
Sólidos totais $(\% \mathrm{~m} / \mathrm{m})$ & 16.03 & 1.22 & 16.05 & 1.51 & 0,8535 & 0,0007 & 0,8719 \\
ESD $(\% \mathrm{~m} / \mathrm{m})$ & 9.74 & 0.31 & 9.75 & 0.39 & 0,9280 & 0,1543 & 0,7369 \\
CCS $(\mathrm{x} 1000 / \mathrm{mL})$ & 171.68 & 277.51 & 329.90 & 581.55 & 0,6135 & 0,0001 & 0,6666 \\
Eletrocondutividade & 2.81 & 0.34 & 2.87 & 0.37 & 0,7419 & 0,0001 & 0,5553 \\
$(\mathrm{mS} / \mathrm{cm})$ & & & & & &
\end{tabular}

ESD - extrato seco desengordurado; CCS -contagem de células somáticas.

Percebe-se, nos resultados avaliados, que não houve um efeito positivo da rbST na produção de leite das búfalas tratadas $(\mathrm{P}>0,05)$ (Fig.1; Painel A). Esses resultados são semelhantes aos obtidos por Jabbar et al. (2007), que verificaram o efeito do uso prolongado de rbST sobre a produtividade em búfalas da raça Nili-Ravi pluríparas em lactação, distribuídas em três grupos: animais tratados com 250mg de rbST com intervalo de 14 dias; 36mg de rbST em dias alternados; e búfalas controle que não receberam rbST. Os autores não constataram diferença significativa na produção média de leite entre os tratamentos. Em contrapartida, as pesquisas de Jorge et al. (2002), Mishra e Shukla (2004) e Hedal e Lasheen (2008) descreveram aumentos significativos na produção de leite de búfalas tratadas com rbST.

Mishra e Shukla (2004) observaram aumento de $25 \%$ na produção de leite $(\mathrm{P}<0,001)$ de búfalas tratadas com três aplicações quinzenais de 250mg de rbST (Boostin-Chemicals, India Pvt.Ltd), a partir de 60 DEL, com aumento significativo na produção entre a quarta e a sétima semana, de nove semanas estudadas. Helal e Lasheen (2008) também verificaram o incremento na produção de leite de búfalas que receberam $500 \mathrm{mg}$ de rbST a cada 14 dias no período de duas semanas antes do parto até a $16^{\mathrm{a}}$ semana de lactação. Por fim, Jorge et al. (2002) observaram incremento de $48,5 \%$ na produção de leite nas búfalas tratadas com 500mg de rbST (Boostin - Mallinckrodt Vet. Ltda.) a cada 14 dias, durante sete meses, sendo a primeira aplicação realizada 10 dias antes da data prevista do parto. Dessa forma, verifica-se que a maioria dos trabalhos indicaram aumento significativo da produção de leite com o uso de rbST em búfalas, diferentemente da presente pesquisa, ressaltandose que, nos referidos estudos, a administração de rbST teve início no período pré-parto. Possivelmente essa modalidade de tratamento tenha contribuído para a obtenção dos resultados.

A resposta à rbST varia consideravelmente dependendo da espécie, da modalidade de tratamento, do estádio de lactação e da nutrição animal (Baldi, 1999). Dessa forma, o não incremento significativo na produção de leite nas búfalas do presente experimento, pode estar associado a alguns fatores, como o estádio da lactação em que o rbST foi aplicado e, sobretudo, o manejo nutricional, em que o fornecimento de concentrado era feito sem considerar a produção de leite. Isso pode ter induzido a menor resposta ao hormônio, conforme também observaram Santos et al. (2001).

A concentração de gordura láctea também não foi influenciada pela aplicação da rbST (Fig.1; Painel B). Esses resultados são semelhantes aos obtidos por outros pesquisados em búfalas (Srinivasa-Rao e Ranganadham, 2000; Helal e Lasheen, 2008; Feckinghaus, 2009; Prasad e Singh, 2010; Melo et al., 2013). Segundo Ferreira et al. (2002), o não efeito da administração da rbST nos níveis de gordura láctea pode estar associado ao status energético do animal, pois animais em balanço energético positivo (BEP) não tiveram alteração na porcentagem de gordura do leite, diferentemente daqueles em balanço energético negativo, que tiveram aumento da gordura do leite, pois um dos precursores desse constituinte do leite (ácidos graxos de cadeia longa) é oriundo dos lipídios circulantes no sangue, derivado da dieta 
e do tecido adiposo mobilizado pelo rbST (Stelwagen et al., 1992). Dessa forma, sugere-se que as búfalas estudadas na presente pesquisa mantiveram-se em BEP, principalmente no que tange ao balanço de nutrientes entre a produção de leite $v s$. a ingestão de nutrientes.

A concentração média da proteína láctea ao longo do experimento foi de $3,86 \%$ no tratamento com rbST e de $3,81 \%$ no grupo controle (Fig. 1; Painel C), não havendo diferença entre os grupos $(\mathrm{P}>0,05)$, corroborando os resultados obtidos por Srinivasa-Rao e Ranganadham (2000), Jorge et al. (2002), Helal e Lasheen (2008) e Melo et al. (2013), que não encontraram efeito da aplicação de rbST sobre a concentração de proteína no leite de búfalas. Entretanto, outros estudos verificaram que a proteína láctea em búfalas é influenciada pela administração da rbST (Prasad e Singh, 2010; Feckinghaus, 2009), diminuindo seus valores de acordo com as aplicações de rbST. O quadro de diminuição da proteína no leite pode ser consequência do balanço negativo de nitrogênio. Quando a rbST acentua o quadro de catabolismo, a diminuição da proteína láctea pode ocorrer se houver algum aumento na produção de leite, o que não foi verificado no presente ensaio.

Não foi observada qualquer influência do rbST sobre os teores de lactose no leite das búfalas $(\mathrm{P}>0,05)$. Durante o período do experimento, os teores de lactose no grupo tratado com 500mg de rbST ao longo da lactação variaram entre $3,80 \%$ e $5,40 \%$, enquanto no grupo controle oscilaram entre $4,20 \%$ e $5,40 \%$ (Fig.1; Painel D), estando na faixa de normalidade para os valores de lactose no leite bubalino descritos por Coelho et al. (2004) e Figueiredo et al. (2010). Outros estudos também não verificaram alteração nos teores de lactose em função da administração de rbST em búfalas leiteiras (Srinivasa-Rao e Ranganadham, 2000; Tarazon-Herrera et al., 2000; Feckinghaus, 2009; Melo et al., 2013).

Os resultados obtidos mostram não haver influência da aplicação de rbST nos teores de sólidos totais no leite das búfalas em estudo. Durante o período do experimento, os teores de sólidos totais no grupo tratado com $500 \mathrm{mg}$ de rbST oscilaram entre $12,30 \%$ e $20,00 \%$, enquanto no grupo controle variaram entre $12,10 \%$ e $18,80 \%$ (Fig.1; Painel E), constatandose valores similares aos descritos por Coelho et al. (2004); Figueiredo et al. (2010). Verificou-se que os resultados de sólidos totais obtidos na presente pesquisa são análogos aos relatados por Feckinghaus (2009) e Melo et al. (2013), em bubalinos, e por Tarazon-Herrera et al. (2000), em bovinos. Uma vez que a gordura é o sólido constituinte majoritário do leite de búfalas, qualquer modificação em suas proporções poderá influenciar o teor de sólidos totais do leite (Cerón-Muñoz et al., 2002). No entanto, como a administração de rbST não afetou a concentração de gordura no leite, o teor de sólidos totais também não foi influenciado.

Os resultados indicam não haver diferença entre os tratamentos $(\mathrm{P}>0,05)$ nos teores de extrato seco desengordurado (ESD). Durante o período do experimento, os teores de ESD no grupo tratado com 500mg de rbST oscilaram entre $9,66 \%$ e $9,97 \%$, e no grupo controle variaram entre $9,64 \%$ e $9,84 \%$ (Fig.1; Painel F), confirmando os valores descritos para os níveis desse composto no leite bubalino por Coelho et al. (2004) e Figueiredo et al. (2010). A concentração de ESD encontrada neste estudo está abaixo do valor médio de 10,47\%, descrito por Macedo et al. (2001), em búfalas da raça Murrah, no oeste do estado de São Paulo, e semelhante aos verificados por Araújo et al. (2011), em búfalas do Rio Grande do Norte, 9,93 e 10,02\%, nos períodos chuvoso e seco, respectivamente. O ESD é composto pelas frações de proteína, lactose e cinzas e depende dos teores individuais destes sólidos e do teor de gordura no leite (Lucena, 2003). Portanto, da mesma forma como os outros constituintes do leite, o ESD também não sofreu influência do tratamento com rbST.

Os resultados obtidos na presente pesquisa mostraram não haver diferença $(\mathrm{P}>0,05)$ da CCS entre os tratamentos e o período experimental. Durante o período do experimento, os valores da contagem de células somáticas no grupo tratado com 500mg de rbST oscilaram entre 4 e 795 (x $1000 / \mathrm{mL}$ ), enquanto no grupo controle oscilaram entre 3 e 1988 (x 1000/mL) (Fig.1; Painel G). Esses resultados estão em concordância com estudos realizados por Tarazon-Herrera et al. (2000), Dohoo et al. (2003), Feckinghaus (2009) e Melo et al. (2013), uma vez que os valores referentes a esse parâmetro não sofreram qualquer influência decorrente do tratamento instituído em búfalas. 


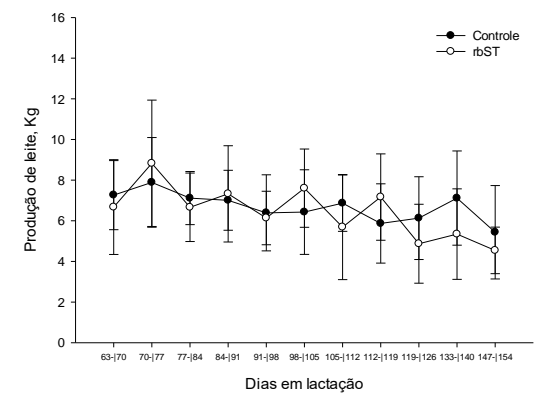

$\mathrm{C}$

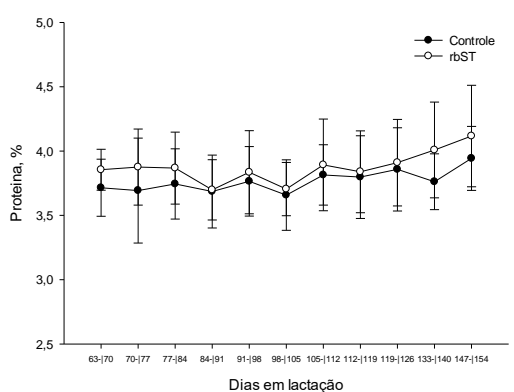

$\mathrm{E}$

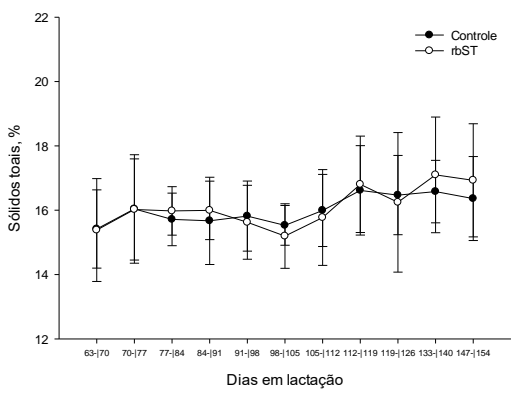

G

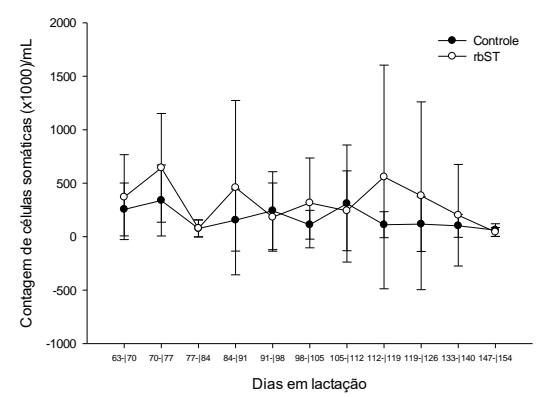

B

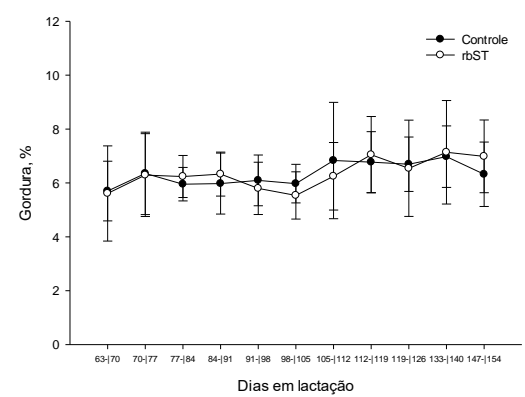

$\mathrm{D}$

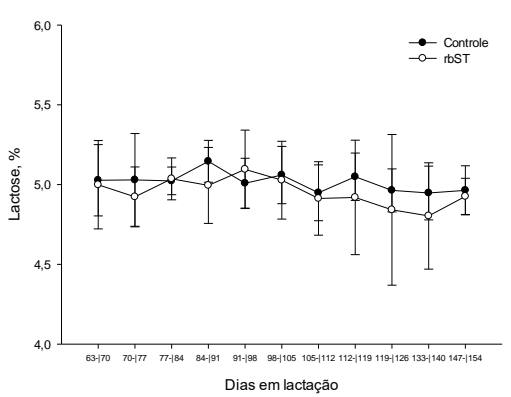

$\mathrm{F}$

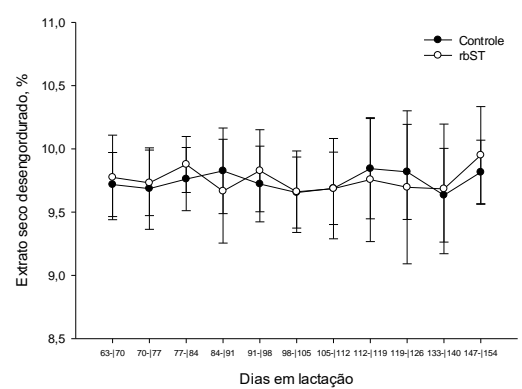

$\mathrm{H}$

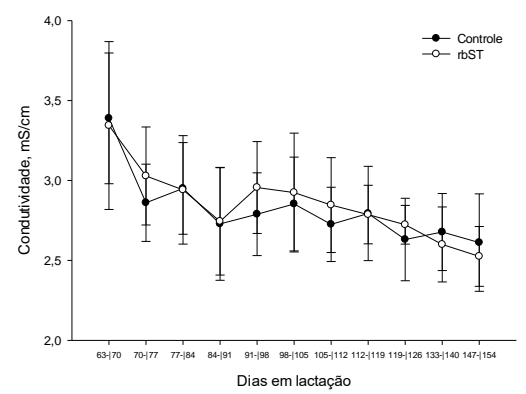

Figura 1. Constituintes e contagem de células somáticas (CCS) do leite de búfalas leiteiras ao longo da lactação, que foram tratadas com somatotropina recombinante bovina (rbST) ou não (controle). Painel A produção de leite $(\mathrm{kg})$; Painel B - gordura do leite $(\% \mathrm{~m} / \mathrm{m})$; Painel C - proteína do leite $(\% \mathrm{~m} / \mathrm{m})$; Painel D - lactose do leite $(\% \mathrm{~m} / \mathrm{m})$; Painel E - sólidos totais do leite $(\% \mathrm{~m} / \mathrm{m})$; Painel F- extrato seco desengordurado do leite $(\% \mathrm{~m} / \mathrm{m})$; Painel $\mathrm{G}$ - contagem de células somáticas do leite $(\mathrm{x} 1000) / \mathrm{mL})$; Painel $\mathrm{H}$ - eletrocondutividade $(\mathrm{mS} / \mathrm{cm})$. 
Não foi observada diferença nos valores médios de eletrocondutividade no leite bubalino entre os tratamentos e os períodos experimentais estudados. Os valores de eletrocondutividade no grupo tratado com $500 \mathrm{mg}$ de rbST oscilaram entre 2,20 e $4,30 \mathrm{mS} / \mathrm{cm}$, enquanto no grupo controle entre 2,20 e 4,0mS/cm (Fig. 1; Painel H). Essses resultados são inferiores aos encontrados por Bastos e Birgel (2011) em búfalas criadas no estado de São Paulo, 3,82 $\pm 0,27$ e 4,49 \pm $0,89 \mathrm{mS} / \mathrm{cm}$. De acordo com Santos e Fonseca (2007), a condutividade elétrica apresenta-se aumentada no leite oriundo de animais com mamite em razão da elevação na concentração de íons $\mathrm{Na}^{+}$e $\mathrm{Cl}^{-}$; dessa forma, é utilizada, em algumas vezes, como indicativo de doença. Destarte, a somatotropina bovina recombinante não induziu à mamite, haja vista que os valores de células somáticas e condutividade elétrica não foram alterados com sua aplicação.

\section{CONCLUSÃO}

A utilização de 500mg de rbST administrados a cada 14 dias, entre 63 e 154 dias em lactação, não altera a produção de leite, tampouco os teores de gordura, proteína, lactose, sólidos totais, ESD, CCS e eletrocondutividade do leite de búfalas leiteiras criadas a pasto.

\section{REFERÊNCIAS}

ARAÚJO, T.P.M.; RANGEL, A.H.N.; SOARES, A.D. et al. Influência das estações do ano sobre a composição do leite de búfalas mantido em tanque de resfriamento. Agropecu. Cient. Semi-Árido, v.07, p.01-05, 2011.

AZEVEDO, J.C.; SANTOS, E.R.D.; MENDES NETO, L.O.R. et al. Produção de leite no dia do controle de búfalas leiteiras no estado do Pará. In: CONGRESSO INTERNACIONAL DE ZOOTECNIA ZOOTEC, 13., 2011, Maceió. Anais... Maceió: [s.n], 2011. p.1-3. (Resumo).

BALDI, A. Manipulating of milk production and quality by use of somatotropin in dairy ruminants other than cow. Domest. Anim. Endocrinol., v.17, p.131-137, 1999.

BASTOS, P.A.S.; BIRGEL, E.H. Leite de búfalas Murrah, criadas em São Paulo (Brasil): influência da idade, fase de lactação, momento da ordenha e isolamento bacteriano na composição físico-química e celular. Rev. Educ. Cont. Vet. Med. Zootec., v.9, p.6-13, 2011.
BAUMAN, D.E. Bovine somatotropin: review of an emerging animal technology. J. Dairy Sci., v.75, p.3432-3451, 1992.

CERÓN-MUÑOZ, M.F.; TONHATI, M.; DUARTE, J. et al. Factors affecting somatic cell counts and their relations with milk and milk constituent yield in buffaloes. J. Dairy Sci., v.85, p.2885-2889, 2002.

COELHO, K.O; MACHADO, P.F.; COLDEBELLA, A. et al. Determinação do perfil físico-químico de amostras de leite de búfalas, por meio de analisadores automatizados. Cienc. Anim. Bras., v.5, p.167-170, 2004.

DOHOO, I.R.; DESCÔTEAUX, L.; LESLIE, K. et al. A meta-analysis review of the effects of recombinant and culling. Can. J. Vet. Res., v.67, p.252-264, 2003.

FECKINGHAUS, M.A. Influência da aplicação da somatotropina recombinante bovina (rbST) no lipidograma e composição do leite de bubalinos da raça Murrah em lactação. 2009. 89f. Dissertação (Mestrado em Clínica Veterinária). Universidade de São Paulo, São Paulo, SP.

FERREIRA, A.T.; SOUZA, J.C.; PEREIRA, M.N. et al. Influência da somatotropina bovina recombinante (rbst), aplicada um dia após o parto, sobre a produção de vacas da raça Holandês primíparas. Ciênc. Agrotec., ed. esp., p.1568-1574, 2002.

FIGUEIREDO, E.L.; LOURENÇO JÚNIOR, J.B.; TORO, M.J.U. Caracterização físicoquímica e microbiológica do leite de búfala "in natura" produzido no estado do Pará. Rev. Bras. Tecnol. Agroind., v.4, p.19-28, 2010.

GONSALVES NETO, J.; FERNANDES, S.A.A.; SILVA, F.F.; PEDREIRA, M.S. Uso de somatotropina bovina em búfalas: efeitos sobre a produção e composição do leite. Rev. Eletron. Nutritime, v.6, p.1056-1071, 2009.

HELAL, F.I.S.; LASHEEN, M.A. The productive perforance of egyptian dairy buffaloes receiving biosynthetic bovine somatotropin (rbST) with or without monensin. Am. Eurasian J. Agric. Environ. Sci., v.3, p.771777, 2008.

JABBAR, M.A.; AHMAD, I.; JAVID, S. et al. Effect of bovine somatotropic hormone on the productive performance of Nili-Ravi buffaloes. Ital. J. Anim. Sci., v.6, p.1039-1042, 2007. 
JORGE, A.M.; GOMES, M.I.F.V.; HALT, R.C. Efeito da utilização da somatotropina recombinante bovina (bST) sobre a produção de leite em búfalas. Rev. Bras. Zootec., v.31, p.1230-1234, 2002.

LUCENA, J.A. Efeitos da somatotropina recombinante bovina (bst), da raça $e$ da alimentação sobre a produção e a qualidade do leite de cabra na região nordeste do Brasil. 2003. 118f. Tese (Doutorado em Nutrição) Universidade Federal de Pernambuco, Recife, PE.

MACEDO, M.P.; WECHSLER, F.S.; RAMOS, A.A. et al. Composição físico-química e produção de leite de búfalas da raça Mediterrâneo no Oeste do Estado de São Paulo. Rev. Bras. Zootec., v.30, p.1084-1088, 2001.

MELO, W.O.; VIANA, R.B.; MONTEIRO, B.M. et al. Produção e composição do leite de búfalas tratadas com somatotropina recombinante bovina no pico de lactação. Acta Vet. Bras., v.7, p.218-228, 2013.

MISHRA, A.; SHUKLA. Effect of recombinant bovine somatotropin (Boostin-250) on blood metabolites and milk yield of lactating buffaloes. Asian-Australas. J. Anim. Sci., v.17, p.12321235, 2004.

PIVATO, I. Aspiração folicular em bovinosefeito do bST. Workshop Reprod. Anim., v.2, p.61-76, 2005.

PRASAD, J., SINGH, M. Milk production and hormonal changes in Murrah buffaloes administered recombinant bovine somatotropin (rbST). Agric. Biol. J. N. Am., v.1, p.1325-1327, 2010.
RODRIGUES, M. Impacto da utilização da somatotropina bovina (bST) sobre a Produção de leite e a avaliação genética de bovinos da raça Holandesa. 2008. 59f. Dissertação (Mestrado em Ciências Biológicas) - Faculdade de Medicina de Ribeirão Preto, Universidade de São Paulo, SP.

SANTOS, M.V.; FONSECA, L.F.L. Estratégia para controle de mastite e melhoria da qualidade do leite. 2.ed. Barueri, SP: Manole, 2007. 314p.

SANTOS, R.A.; TEIXEIRA, J.C.; ABREU, L.R. et al. Efeito de diferentes doses de somatotropina bovina (rbST) na produção e composição do leite. Ciênc. Agrotec. v.25, p.1435-1445, 2001.

SILVA, D.J.; QUEIROZ, A.C.Q. Análise de alimentos: métodos químicos e biológicos. 3.ed. Viçosa, MG: UFV, 2002. 235p.

SRINIVASA-RAO, K.; RANGANADHAM, M. Effect of bovine somatotropin on milk production and composition in lactating Murrah buffaloes. Indian J. Anim. Sci., v.53, p.46-50, 2000.

STELWAGEN, K.; GRIEVE, D.G.; MCBRIDE, B.W.; REHMAN, J.D. Growth and subsequent lactation in primigravid Holsteins heifers after prepartum bovine somatotropin treatment. $J$. Dairy Sci., v.75, p.463-471, 1992.

TARAZON-HERRERA, M.A.; HUBER, J.T.; SANTOS, J.E.P. et al. Effects of bovine somatotropin on milk yield and composition in Holstein cows in avanced lactation fed low or high energy diets. J. Dairy Sci., v.83, p.430-434, 2000. 